\title{
Mineral and phytochemical composition of baobab (Adansonia digitata $L$.) root tubers from selected natural populations of Malawi
}

\section{Mussa Kamanula ${ }^{1}$, Chimuleke R.Y. Munthali ${ }^{1}$, Agnes Dziwapo ${ }^{1}$, John F. Kamanula ${ }^{2}$}

1. Department of Forestry, Mzuzu University, Private Bag 201, Luwinga, Mzuzu

2. Department of Chemistry, Mzuzu University, Private Bag 201, Luwinga, Mzuzu
Date Received: 30-Dec-2017

Revision Received: 08-Jun-2018

Date Accepted: 29-Jun-2018

Correspondence: Mussa Kamanula

(kamanulamussa@yahoo.com)

\begin{abstract}
Background
Abstract

Most studies on baobab have focused mainly on the nutritional value of baobab fruit pulp. Information on nutritional value and medicinal properties of the baobab root tuber has not been fully investigated and is scarce. This study was conducted to assess mineral and phytochemical composition of baobab root tubers from selected natural populations of Malawi.

Methods

Baobab seeds from Chikhwawa, Mwanza, Salima, Karonga and Likoma were sown at Mzuzu University. At the age of five months after sowing, mineral content of the resulting root tubers was determined using atomic absorption spectrophotometer whereas phytochemical composition was determined qualitatively.

Results

Magnesium (44.16mg/100g) and calcium $(69.39 \mathrm{mg} / 100 \mathrm{~g})$ levels were highest in baobab root tubers from Chikhwawa and Karonga, respectively. Mwanza and Karonga root tubers contained highest amount of lead $(0.2100 \mathrm{mg} / 100 \mathrm{~g})$ while iron content was highest $(8.89 \mathrm{mg} / 100 \mathrm{~g})$ in root tubers from Karonga. Salima and Mwanza root tubers showed strong concentration of terpenoids. Moderate concentrations of saponins were detected in Mwanza, Salima, Karonga and Chikhwawa root tubers. Alkaloids and flavonoids were absent in all families from the five sampled provenances.

Conclusion

Minerals and phytochemicals present in baobab root tubers suggest their nutritional and medicinal potential. However, further research is required to establish the causes of high levels of lead in baobab root tubers.
\end{abstract}

Key words: baobab, calcium, iron, lead, magnesium, saponins, terpenoids

\section{Introduction}

Baobab (Adansonia digitata L.) is a deciduous indigenous fruit tree that belongs to the family called Malvaceae and is native to Africa ${ }^{1}$. The tree is found in most of sub-Sahara Africa's semi-arid and sub-humid regions as well as in western Madagascar ${ }^{2}$. In southern Africa, Adansonia digitata is commonly found in Malawi, Mozambique, South Africa and Zimbabwe ${ }^{3}$. In Malawi, Adansonia digitata is mostly found in dry woodlands ${ }^{4}$. It usually grows as a solitary individual though sometimes it can be found in small groups depending on soil type ${ }^{5}$. A baobab tree can grow up to 25 meters in height, 28 meters in girth and can live for several hundred years $^{6}$. It has a shallow root system that rarely extends beyond 2 meters in depth for mature trees ${ }^{4}$. The tree excels in a wide range of well drained soils but not in deep unconsolidated sands3. Fluvisols, which are not subjected to flooding, have been reported to favour the growth of baobab ${ }^{7}$. The species does not occur in water-logged and frost areas ${ }^{5}$. It requires an annual temperature of range $20-30^{\circ} \mathrm{C}$ but can also tolerate high temperatures of $40-42^{\circ} \mathrm{C}^{8}$. Lower altitudes with annual rainfall in the range of $100-1000 \mathrm{ml}$ have been reported to be ideal for the growth of baobab tree ${ }^{1,9}$.

A baobab is a multi-purpose tree mostly valued for food and traditional medicine. The root tubers, twigs, fruits, seeds, leaves and flowers are all edible and have been found to possess various minerals (calcium, iron, copper, manganese, zinc, potassium, magnesium) and phytochemicals ${ }^{8}$.

In addition, a variety of phytochemicals (terpenoids, flavonoids and steroids) which are responsible for medicinal purposes have been chemically isolated from various parts of the baobab tree ${ }^{10}$. Even without such knowledge, rural communities have developed unique indigenous knowledge related to use of traditional medicine ${ }^{11}$. The use of baobab tree parts has been reported to vary from place to place $^{3}$. In Malawi, a study revealed that people in Chikhwawa (56.3\%) and Karonga (46.4\%) utilize baobab root for medicinal purposes $^{12}$. In southern Malawi, an infusion of baobab root has for a long time been used to treat sore throats ${ }^{13}$. The wide ecological adaption of baobab tree suggests the species has evolved a wide genetic diversity across its geographical range ${ }^{12}$. In this regard, it is possible that variations in mineral and phytochemical composition of baobab root tubers are influenced by geographical or genetic differences, hence their use cannot be generalized. This study was carried out to determine the variation in mineral and phytochemical composition of baobab root tubers from selected natural populations of Malawi. This information would be useful for baobab populations whose root tubers are exploited for food and medicinal purposes. In addition, findings of this study will be essential for future selection programmes aimed at producing baobab populations of specific mineral and phytochemical content. 


\section{Methods}

\section{Study area and experimental material}

Baobab seeds representing a total of 59 half-sib families were collected in Malawi from five provenances (Karonga, Salima, Mwanza, Chikhwawa and Likoma). For easy data collection, these provenances were abbreviated as $\mathrm{K}, \mathrm{S}, \mathrm{M}, \mathrm{C}$ and $\mathrm{L}$, respectively. Mature baobab fruits were harvested from trees by plucking and/or collection on the ground. The fruits were collected at the peak of fruit season between April and May, 2008. The fruits were collected from randomly selected parents at a distance of at least $100 \mathrm{~m}$ apart. Fruits were kept in plastic bags and were transferred from provenances to the nursery by car. The fruits were then crushed using stones to obtain seeds that were covered with pulp. Seeds were washed with tap water to remove pulp and then dried. Before sowing, baobab seeds (Orthodox) were stored in plastic bags at room temperature. In October 2015, the seeds were sown at Mzuzu University Forestry department nursery. Table 1 shows site characteristics for the five sampled baobab provenances. The seeds were pretreated through nicking to allow water penetration. Mzuzu University lies in silvicultural zone $\mathrm{M}$ and falls at an altitude of $1270 \mathrm{~m}$ above sea level with mean annual temperature range of $13.5^{\circ} \mathrm{C}$ to $24^{\circ} \mathrm{C}$ and mean annual rainfall of $1150 \mathrm{~mm}^{12}$.

Table 1: Site characteristics for five sampled baobab provenances

\begin{tabular}{|c|c|c|c|c|c|}
\hline Provence & $\begin{array}{l}\text { Silvicultural } \\
\text { zone }\end{array}$ & Altitude (m) & $\operatorname{MAR}(\mathrm{mm})$ & $\mathrm{T}\left({ }^{\circ} \mathrm{C}\right)$ & Soil type \\
\hline Karonga & $L$ & $750-1000$ & $>1600$ & $23-25$ & $\begin{array}{l}\text { Ferrisols, } \\
\text { domant } \\
\text { regosols }\end{array}$ \\
\hline Salima & $\mathrm{Ba}$ & $200-1000$ & $710-850$ & $20-25$ & $\begin{array}{l}\text { Alluvial } \\
\text { calcimorphic } \\
\text { soils }\end{array}$ \\
\hline Mwanza & J & $900-1500$ & $>1200$ & $19-21$ & $\begin{array}{l}\text { Sandy } \\
\text { ferrallitic }\end{array}$ \\
\hline Chikhwawa & A & $<200$ & $710-840$ & $<25$ & Vertisols \\
\hline Likoma & $L$ & $475-1000$ & $>1600$ & $23-25$ & $\begin{array}{l}\text { Ferrisols, } \\
\text { regosols, } \\
\text { lithosols }\end{array}$ \\
\hline
\end{tabular}

Adopted from Hardcastle. ${ }^{14}$

\section{Experimental design}

The trial was laid out as a complete randomized design with four replicates. From 59 baobab families, 25 families were selected for sowing on the basis of seed quality. Seeds which were relatively small and damaged were left. For each treatment, two seeds for each of 25 families were sown in ten black polythene tubes $(30 \mathrm{~cm} \times 15 \mathrm{~cm})$ at $4 \mathrm{~cm}$ depth. Sand and dark-grey miombo soils mixed in the ratio 1:2, respectively, were used as rooting medium. Watering was carried out twice a day to keep the rooting medium moist. After germination, the seedlings were thinned to remain with one seedling per tube.

\section{Collection and processing of baobab root tubers}

At the age of five months after sowing (October 2015 March, 2016), baobab root tubers (Figure 1) were collected from the nursery by uprooting the entire plant. The root tubers were then cleaned to remove mud. Thereafter, the root tubers were sliced into small pieces by sterilized blades.
The samples were then pounded using a mortar and pestle. The wet samples were then weighed $(50 \mathrm{~g})$ and transferred into dry beakers and then dried in an electric oven (Series 9000) at $105^{\circ} \mathrm{C}$ overnight to constant mass.

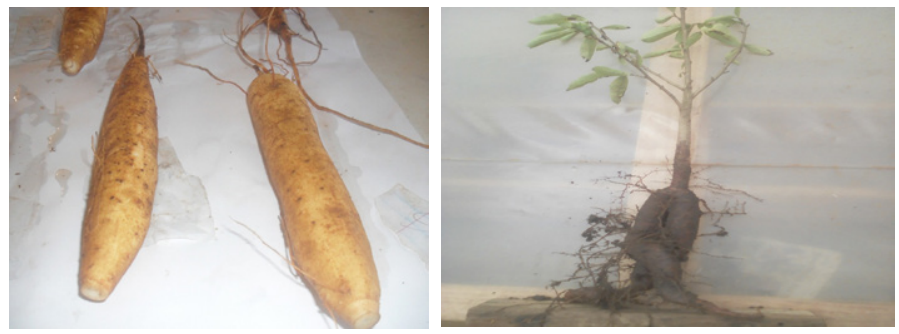

Figure 1: Baobab root tubers

\section{Determination of minerals}

Mineral content of baobab root tubers was determined using atomic absorption spectrophotometer ${ }^{15}$. For each treatment, the dried powdered sample $(5 \mathrm{~g})$ of baobab root tuber was placed in a $50 \mathrm{~mL}$ porcelain crucible in triplicate. The samples were then ashed by heating at a temperature of $650^{\circ} \mathrm{C}$ for 6 hours in an electric muffle furnace (CWF 1200). After cooling, hydrochloric acid solution (6M) was then added $(7 \mathrm{~mL})$ to the ash and boiled on a hot plate with the aid of four anti-bumping granules until the solution had just dried. The crucible containing the sample was removed from the hot plate and hydrochloric acid solution (3M) added (10 $\mathrm{mL}$ ) to it, and boiled for 10 seconds on a hot plate. After cooling, each sample was filtered into $100 \mathrm{ml}$ volumetric flask. Blank sample which contained all reagents except the sample was treated in a similar manner as the samples. The filtered samples were finally diluted with distilled water up to the $100 \mathrm{~mL}$ mark. The sample solutions were then taken to Agricultural Research and Extension Trust (ARET) in Lilongwe for determination of minerals using atomic absorption spectrophotometer (AAS). From each metal calibration curve, the mineral (metal ion) content was calculated using the following formula:

Metal content $(\mathrm{mg} / 100 \mathrm{~g})=[(\mathrm{a}-\mathrm{b}) \mathrm{x} \mathrm{V}] / 10 \mathrm{~W}$

Where $\mathrm{W}$ is the weight $(\mathrm{g})$ of the sample, $\mathrm{V}$ is the volume (mL) of extract (filtered sample); $\mathrm{a}$ and $\mathrm{b}$ are concentrations $(\mathrm{mg} / \mathrm{L})$ of a sample solution and blank determined from a calibration curve, respectively.

\section{Phytochemical screening of baobab root tuber}

Phytochemical screening of baobab root tubers was carried out using qualitative methods ${ }^{16,17,18}$. The analyses were carried out on dry and pounded samples. All the analyses were carried out at Mzuzu University Chemistry laboratory.

\section{Test for alkaloids}

A test for the presence of alkaloids was done using Dragendorff and Mayer's reagents. A dried powdered sample $(5 \mathrm{~g})$ was macerated in $5 \%(\mathrm{v} / \mathrm{v})$ hydrochloric acid solution for 24 hours. Two portions of the filtrate $(1 \mathrm{~mL}$ each) were treated with 10 drops of Dragendorff and Mayer's reagents separately. Absence of the red precipitate and cream white precipitates were taken as an indication for the absence of alkaloids ${ }^{16}$. 


\section{Test for terpenoids}

A dried powdered sample $(1 \mathrm{~g})$ was macerated in $20 \mathrm{~mL}$ of diethyl ether in a stoppered conical flask for 48 hours. A portion of the filtrate $(1 \mathrm{~mL})$ in a porcelain crucible was dried on a hot plate followed by the addition of 10 drops of concentrated sulphuric acid. The colour produced was recorded. Another portion $(1 \mathrm{~mL})$ was treated the same but starting with the addition of acetic anhydride $(1 \mathrm{~mL})$ followed by concentrated sulphuric acid, $1 \mathrm{~mL}$ ). The appearance of green, blue and pink to purple colors indicate the presence of terpenoids ${ }^{16}$.

\section{Test for saponins}

An infusion $(5 \%, \mathrm{w} / \mathrm{v})$ was prepared by macerating $1 \mathrm{~g}$ of dried powdered sample in $20 \mathrm{~mL}$ of distilled water. The mixture was left to stand for 24 hours and the extract was filtered using Whatman filter paper No.1. A portion of the filtrate $(10 \mathrm{~mL})$ was transferred into a test tube and was shaken vigorously for 10 seconds. The foam that persisted for 10 minutes was measured using a ruler and used as an indication for the presence of saponins ${ }^{17}$.

\section{Test for flavonoids}

A dry powdered sample $(5 \mathrm{~g})$ was macerated in $50 \mathrm{~mL}$ of distilled water and the mixture was left to stand for 24 hours. The mixture was then filtered and a solution $(0.5 \mathrm{~mL})$ containing hydrochloric acid, methanol and water (1:1:1) was added to the filtrate followed by some few magnesium turnings. Absence of the pink or red colour was used to indicate absence of flavonoids ${ }^{18}$.

\section{Data analysis}

Data for mineral composition of baobab root tubers from 25 families were tested for normality and homogeneity with Komolgorov-Smirnov using Minitab 16. After meeting the two criteria, data were subjected to one-way ANOVA at $(\mathrm{P}=0.05)$ using the same statistical package. Means were separated using Fisher's test. The concentration of phytochemicals was assessed using qualitative scores $(+++$, $++,+,-)$ where +++ denoted strong concentration, ++ representing moderate concentration, + indicating weak concentration and - indicating absence of a particular phytochemical.

\section{Results}

\section{Mineral composition of baobab root tubers}

Variations of mineral elements in all the treatments are summarized in Table 2. There were great variations in the mineral content of baobab root tubers among the study populations.

Table 2: Variation in mineral content of baobab root tubers

\begin{tabular}{llllll}
\hline Element & $\begin{array}{l}\text { Mean } \\
(\mathrm{mg} / 100 \mathrm{~g})\end{array}$ & S.E. Mean & Interval & Variance & Variance\% \\
\hline $\mathrm{Mg}$ & 22.72 & 1.89 & $8.41-56.01$ & 47.60 & 565.99 \\
$\mathrm{Ca}$ & 42.91 & 2.60 & $15.89-123.39$ & 107.50 & 676.53 \\
$\mathrm{~K}$ & 6.608 & 0.267 & $3.180-10.300$ & 7.12 & 223.89 \\
$\mathrm{Fe}$ & 5.141 & 0.22 & $2.10-10.59$ & 8.49 & 404.29 \\
$\mathrm{Cu}$ & 0.0694 & 0.0052 & $0.0200-0.1900$ & 0.17 & 850 \\
$\mathrm{Zn}$ & 0.2212 & 0.0131 & $0.1100-0.6400$ & 0.53 & 481.81 \\
$\mathrm{Mn}$ & 0.491 & 0.0181 & $0.2600-1.0400$ & 0.93 & 357.69 \\
$\mathrm{Cd}$ & 0.01475 & 0.0015 & $0.0014-0.0364$ & 0.035 & 2500
\end{tabular}

Table 3: Mineral content of baobab root tubers for 25 families in five provenances

\begin{tabular}{|c|c|c|c|c|c|c|c|c|c|}
\hline & & & Miner & ent $(\mathrm{mg} /$ & & & & & \\
\hline Code & $\mathrm{Mg}$ & $\mathrm{Ca}$ & K & $\mathrm{Fe}$ & $\mathrm{Cu}$ & $\mathrm{Zn}$ & $\mathrm{Mn}$ & $\mathrm{Cd}$ & $\mathrm{Pb}$ \\
\hline C10 & $11.11^{d}$ & $28.54^{\text {ff }}$ & $8.59^{\mathrm{a}}$ & $6.13^{b}$ & $0.035^{\circ}$ & $0.170^{\mathrm{a}}$ & $0.470^{\circ}$ & $0.014^{10}$ & $0.185^{\circ}$ \\
\hline $\mathrm{C} 2$ & $44.16^{a}$ & $33.44^{d}$ & $6.94^{\circ}$ & $5.30^{\circ}$ & $0.0900^{1}$ & $0.170^{a}$ & $0.355^{\circ}$ & 0.0296 & $0.025^{\circ}$ \\
\hline C3 & $34.79^{\circ}$ & $26.45^{\circ}$ & $7.51^{\mathrm{a}}$ & $3.95^{\circ}$ & $0.0600^{c}$ & $0.165^{\mathrm{a}}$ & $0.460^{c}$ & $0.023^{\circ}$ & $0.030^{\circ}$ \\
\hline$C 5$ & $9.840^{\circ}$ & $43.26^{\circ}$ & $4.35^{\mathrm{a}}$ & $4.69^{b}$ & $0.030^{d}$ & $0.170^{a}$ & $0.355^{\dagger}$ & 0.0090 & 0.195 \\
\hline $\mathrm{Cb}$ & $39.299 \mathrm{ab}$ & $38.42^{d}$ & $7.81^{\mathrm{a}}$ & $3.13^{d}$ & $0.085^{5 c}$ & $0.170^{a}$ & $0.450^{c}$ & $0.030^{30}$ & 0.045 \\
\hline K11 & 13.91 & $35.14^{d}$ & $5.30^{\mathrm{a}}$ & $4.86^{b}$ & $0.025 e$ & $0.155^{\mathrm{a}}$ & $0.420^{\circ}$ & $0.0077^{\circ}$ & $0.190^{\circ}$ \\
\hline K12 & 15.28 & $69.39^{\mathrm{a}}$ & $8.96^{\circ}$ & $5.57^{b}$ & $0.045^{\circ}$ & $0.255^{\mathrm{a}}$ & $0.665^{b}$ & $0.0088^{\circ}$ & 0.155 \\
\hline$K 3$ & $13.17^{d}$ & $47.93^{\circ}$ & $5.34^{a}$ & $7.25^{a b}$ & $0.035^{d}$ & $0.415^{\mathrm{a}}$ & $0.465^{\circ}$ & $0.007^{\circ}$ & 0.070 \\
\hline$K 5$ & $19.60^{d}$ & $62.65^{20 \mathrm{~b}}$ & $7.59^{\mathrm{a}}$ & $5.98^{b}$ & $0.025^{e}$ & $0.210^{a}$ & $0.545^{b c}$ & $0.005^{\circ}$ & 0.120 \\
\hline K8 & 19.32 & $47.37^{\circ}$ & $5.65^{\mathrm{a}}$ & $8.89^{\mathrm{a}}$ & $0.025^{e}$ & $0.320^{a}$ & $0.815^{2}$ & $0.007^{\circ}$ & $0.210^{-}$ \\
\hline L2 & 32.996 & $25.72^{e}$ & $7.30^{\mathrm{a}}$ & $4.04^{b c}$ & $0.070^{b}$ & $0.155^{\mathrm{a}}$ & $0.465^{\circ}$ & $0.026^{b}$ & 0.065 \\
\hline L3 & $14.24^{d}$ & 54.196 & $5.15^{a}$ & $3.84^{\circ}$ & $0.085^{\circ}$ & $0.185^{a}$ & $0.630^{\circ}$ & $0.007{ }^{\circ}$ & 0.175 \\
\hline L4 & $12.39 \mathrm{~d}$ & $32.85^{\circ}$ & $6.07^{2}$ & $3.46^{\circ}$ & $0.045^{\circ}$ & $0.160^{\mathrm{a}}$ & $0.440^{\circ}$ & 0.0090 & 0.190 \\
\hline L7 & $39.05^{300}$ & 25.02 & $9.78^{a}$ & $6.87^{\circ}$ & $0.110^{b}$ & $0.145^{\mathrm{a}}$ & $0.495^{\circ}$ & $0.034^{\mathrm{a}}$ & $0.040^{\circ}$ \\
\hline 19 & $38.84^{200}$ & $42.65^{\circ}$ & $4.88^{a}$ & $3.41^{b c}$ & $0.110^{b}$ & $0.155^{\mathrm{a}}$ & $0.470^{\circ}$ & $0.027^{\circ}$ & 0.075 \\
\hline M13 & $14.81 \mathrm{~d}$ & $49.85^{\circ \mathrm{cc}}$ & $5.01^{3}$ & $3.810 \mathrm{cc}$ & $0.0800^{\text {bc }}$ & $0.230^{\mathrm{a}}$ & $0.495^{\circ}$ & $0.0077^{\circ}$ & $0.130^{\circ}$ \\
\hline M15 & $10.30^{d}$ & $44.26^{\circ}$ & $7.84^{\mathrm{a}}$ & $4.23^{b}$ & $0.045^{\circ}$ & $0.235^{\mathrm{a}}$ & $0.450^{\circ}$ & $0.007^{\circ}$ & $0.210^{2}$ \\
\hline M3 & $27.52^{\circ}$ & $33.50^{d}$ & $7.92 \mathrm{a}$ & $7.077^{20}$ & $0.105^{\circ}$ & $0.345^{\mathrm{a}}$ & $0.490^{\circ}$ & 0.008 & 0.145 \\
\hline M7 & $12.37^{d}$ & $43.14^{\circ}$ & $4.67^{\mathrm{a}}$ & $5.61^{\mathrm{b}}$ & $0.0800^{\text {bc }}$ & $0.210^{a}$ & $0.610^{b}$ & $0.002 d$ & $0.130^{\circ}$ \\
\hline M9 & $40.48^{300}$ & $27.72^{\mathrm{ef}}$ & $6.09^{\mathrm{a}}$ & $5.30^{b}$ & $0.125^{\circ}$ & $0.180^{\mathrm{a}}$ & $0.3855^{d \mathrm{~d}}$ & $0.028^{\circ}$ & 0.025 \\
\hline$S 11$ & $11.77^{d}$ & $51.18^{b}$ & $5.99^{a}$ & $5.63^{b}$ & $0.055^{\circ}$ & $0.275^{\mathrm{a}}$ & $0.470^{\circ}$ & 0.008 & 0.185 \\
\hline$S 13$ & $32.10^{b}$ & $28.78^{8}$ & $5.84^{a}$ & $4.97^{\circ}$ & 0.090 bec & $0.180^{a}$ & $0.405^{\circ}$ & $0.029^{\circ}$ & 0.025 \\
\hline$S 15$ & $39.16^{\mathrm{ab}}$ & $39.91^{\mathrm{d}}$ & $6.49^{\mathrm{a}}$ & $5.66^{b}$ & $0.155^{\mathrm{a}}$ & $0.275^{\mathrm{a}}$ & $0.550^{\mathrm{bc}}$ & $0.025^{\circ}$ & $0.040^{\circ}$ \\
\hline S2 & $12.93^{d}$ & $58.45^{b}$ & $7.66^{\mathrm{a}}$ & $4.12^{\circ}$ & $0.050^{c}$ & $0.360^{\mathrm{a}}$ & $0.515^{\circ x}$ & $0.007^{\circ}$ & $0.190^{\circ}$ \\
\hline S6 & $12.10^{d}$ & 43.010 & $6.42^{8}$ & $5.15^{b}$ & $0.075^{50}$ & $0.265^{3}$ & $0.625^{\circ}$ & $0.0077^{\circ}$ & $0.180^{\circ}$ \\
\hline $\begin{array}{l}\text { Pooled } \\
\text { StDv }\end{array}$ & 5.64 & 14.91 & 1.735 & 0.91 & 0.019 & 0.08 & 0.086 & 0.003 & 0.038 \\
\hline
\end{tabular}

\section{C = Chikhwawa, $\mathrm{K}=$ Karonga, $\mathrm{L}=$ Likoma, $\mathrm{S}=$ Salima, $\mathbf{M}=$ Mwanza}

*Means with different superscripts within a column are statistically different.

Generally, calcium was shown to be the highest mineral $(42.91 \pm 2.60 \mathrm{mg} / 100 \mathrm{~g})$ present in the baobab families under study whilst the least mineral was cadmium $(0.01475 \pm 0.0015 \mathrm{mg} / 100 \mathrm{~g})$. The variance percentage ranged from $223.89 \%$ for $\mathrm{K}$ to $2500 \%$ for $\mathrm{Pb}$ and $\mathrm{Cd}$. Variations of mineral elements in all the treatments are summarized in Table 3. There were significant differences $(\mathrm{P}<0.05)$ in the amount of magnesium $(\mathrm{Mg})$, calcium $(\mathrm{Ca})$, iron $(\mathrm{Fe})$, copper $(\mathrm{Cu})$, manganese $(\mathrm{Mn})$, cadmium $(\mathrm{Cd})$ and lead $(\mathrm{Pb})$ among the families. No significant differences $(\mathrm{P}>0.05)$ were observed in the levels of potassium $(\mathrm{K})$ and zinc $(\mathrm{Zn})$ among the families. Highest amount of magnesium (44.160mg/100g) was recorded in a family from Chikhwawa (C2) while the lowest amount of magnesium $(9.84 \mathrm{mg} / 100 \mathrm{~g})$ was also detected in a family from Chikhwawa (C5). Calcium levels were highest $(69.39 \mathrm{mg} / 100 \mathrm{~g})$ in Karonga family (K12) and lowest $(25.02 \mathrm{mg} / 100 \mathrm{~g})$ in a family from Likoma (L7). Iron content was highest $(8.89 \mathrm{mg} / 100 \mathrm{~g})$ in Karonga family (K8) and lowest $(3.13 \mathrm{mg} / 100 \mathrm{~g})$ in a family from Chikhwawa (C6). Levels of copper were highest $(0.155 \mathrm{mg} / 100 \mathrm{~g})$ in Salima 
family (S15) and lowest $(0.0250 \mathrm{mg} / 100 \mathrm{~g})$ in three families from Karonga (K11, K5 and K8). The highest amount of manganese $(0.815 \mathrm{mg} / 100 \mathrm{~g})$ was found in a family from Karonga (K8) while the lowest amount $(0.335 \mathrm{mg} / 100 \mathrm{~g})$ was detected in two families from Chikhwawa (C2 and C5). Cadmium levels were highest $(0.0343 \mathrm{mg} / 100 \mathrm{~g})$ in a family from Likoma (L7) and lowest $(0.0024 \mathrm{mg} / 100 \mathrm{~g})$ in a family from Mwanza (M7). The highest amount of lead $(0.2100 \mathrm{mg} / 100 \mathrm{~g})$ was recorded in families from Mwanza (M15) and Karonga (K8) while lowest levels (0.025mg/100g) of lead were found in families from Chikhwawa (C2), Salima (S13) and Mwanza (M9).

\section{Phytochemical variation of baobab root tubers}

Table 4 shows phytochemical composition of $A$. digitata root tubers from the five study areas. Root tubers from Salima and Mwanza showed strong concentration of terpenoids Moderate concentrations of terpenoids were observed in root tubers from Karonga and Chikhwawa while weak concentrations were recorded in root tubers from Likoma. Moderate concentrations of saponins were detected in root tubers from Mwanza, Salima, Karonga and Chikhwawa while weak concentrations were recorded in root tubers from Likoma. Alkaloids and flavonoids were absent in root tubers from all the five provenances.

Table 4: Phytochemical variation of baobab root tubers from five provenances

\begin{tabular}{lllll}
\hline & \multicolumn{4}{c}{ Phytochemical } \\
\cline { 2 - 5 } Provenance & Terpenoids & Saponins & Alkaloids & Flavonoids \\
\hline Mwanza & +++ & ++ & - & - \\
Salima & +++ & ++ & - & - \\
Karonga & ++ & ++ & - & - \\
Chikhwawa & ++ & ++ & - & - \\
Likoma & + & + & - & - \\
\hline
\end{tabular}

\section{Discussion}

This study has shown that the mineral content and phytochemical composition of baobab root tubers from different geographical localities of Malawi differ significantly when raised in the same environment. Variations have been reported to arise from genetic and environmental differences ${ }^{19,20}$. Differences in the mineral content and phytochemical composition of baobab root tubers in this study could, therefore, be attributed to genetics as all the families were raised in the same environment. This conclusion supports earlier hypothesis that baobab has evolved a wide genetic diversity across its geographical range ${ }^{12}$. It could be possible that the species utilizes its long life span in successfully adapting to various climatic and environmental effects in different geographical localities. The high variance percentages (Table 2) in the important minerals $(\mathrm{Mg}, \mathrm{Ca}, \mathrm{K}$, $\mathrm{Fe}, \mathrm{Cu}, \mathrm{Zn})$ present in baobab root tubers clearly show the possibility of selection at family level. The effect of various quantitative trait loci generally explains the genetic variance in the mineral content of specific organisms ${ }^{21}$.

Magnesium is important in protein synthesis, release of energy from muscle storage and is essential in regulating body temperature ${ }^{22}$. High levels of magnesium $(44.16 \mathrm{mg} / 100 \mathrm{~g})$ in Chikhwawa family (C2) suggest baobab root tubers are an important source of magnesium for nutritional purposes. Moreover magnesium levels (44.160mg/100g) in this study are higher than reported values in raw sweet potatoes $(30 \mathrm{mg} / 100 \mathrm{~g})$, cassava $(16 \mathrm{mg} / 100 \mathrm{~g})$ and yams $(17 \mathrm{mg} / 100 \mathrm{~g})^{22}$. Calcium is very important in tooth formation and reduces the risk of osteoporosis, a condition in which decreased bone mass weakens the bone ${ }^{22}$. In all the families, calcium levels $(25.02 \mathrm{mg} / 100 \mathrm{~g}-60.39 \mathrm{mg} / 100 \mathrm{~g})$ were much higher compared to lower levels $(18.20 \mathrm{mg} / 100 \mathrm{~g})$ recorded in baobab leaves ${ }^{22}$. The high content of calcium $(69.39 \mathrm{mg} / 100 \mathrm{~g})$ in baobab root tubers indicates that they may be used to improve tooth and bone strength. Potassium plays an important role in lowering blood pressure and release of energy from fats, proteins and carbohydrates ${ }^{23}$. Statistical insignificant levels of potassium among the study populations indicates that its content is the same in different geographical localities of Malawi. Iron is a major component of hemoglobin and has been reported to be very important in the oxidation of carbohydrate, protein and fats ${ }^{24}$. High iron levels found in this study $(8.89 \mathrm{mg} / 100 \mathrm{~g})$ in Karonga (K8) are greater than the value $(3.95 \mathrm{mg} / 100 \mathrm{~g})$ recorded in dry baobab fruit pulp by Phytotrade Africa ${ }^{25}$. Iron content could therefore support use of baobab roots in improving levels of hemoglobin as well as the general human nutrition. Manganese supports brain functioning and is required for blood sugar regulation ${ }^{22}$. High levels (Table 3 ) of manganese $(0.185 \mathrm{mg} / 100 \mathrm{~g})$ in Karonga (K8) indicate potential use in treating diabetes. Furthermore, Mn levels recorded in this study $(0.185 \mathrm{mg} / 100 \mathrm{~g})$ are higher compared to Mn content $(0.035 \mathrm{mg} / 100 \mathrm{~g})$ in raw apple and avocado $(0.095 \mathrm{mg} / 100 \mathrm{~g})^{22}$. Zinc is involved in digestion, metabolism and is an important antioxidant ${ }^{22}$. Zinc levels $(0.2212 \mathrm{mg} / 100 \mathrm{~g})$ among the study populations indicate that its content in baobab root tuber is also the same across geographical localities of Malawi. However, the amount of $\mathrm{Zn}(0.221 \mathrm{mg} / 100 \mathrm{~g})$ recorded in this study is lower compared to levels $(0.680 \mathrm{mg} / 100 \mathrm{~g})$ found in avocado ${ }^{22}$. Copper is a redox active metal necessary for the formation of hemoglobin and is required for the function of over 30 proteins ${ }^{26}$. Presence of copper in baobab root tubers in this study indicates potential use in prevention of anemia and malnutrition deficiencies common in Malawi. However, the levels of copper $(0.025-0.155 \mathrm{mg} / 100 \mathrm{~g})$ found in this study are very low compared to copper levels $(13.00 \mathrm{mg} / 100 \mathrm{~g})$ reported in baobab leaves ${ }^{24}$. Lead is an element that is not needed in the body ${ }^{27}$. Levels of lead $(>0.03 \mathrm{mg} / 100 \mathrm{~g})$ may cause impairment of the central nervous system in children $^{27}$. High levels of lead reported in this study could be due to that the soil where the baobab tubers were growing was contaminated by lead. However, the validity of this hypothesis would be true only if the soil was analysed before and after the experiment for the presence of lead. Cadmium is an inorganic metal that causes anemia and heart diseases if ingested in high concentrations ${ }^{27}$. High levels of Cadmium $(0.0343 \mathrm{mg} / 100 \mathrm{~g})$ in population from Likoma (L7) indicate a health concern in the utilization of baobab root tuber either for food or medicinal purposes. A study in Nigeria failed to detect lead but found cadmium levels $(0.85 \mathrm{mg} / 100 \mathrm{~g})$ in baobab leaves and reported that lead and cadmium are naturally present in the environment ${ }^{24}$. As mentioned earlier, in the current study, soil samples and water used in the experiment were not tested for the presence of lead and cadmium. It could be possible that high levels of lead and cadmium were attributed to the soil and water used in the experiment. Still more, presence of lead and cadmium in baobab root tubers could be genetically influenced. Further research is required to establish the sources of high levels 
of lead and cadmium in baobab roots. In southern Malawi, children consume baobab root tuber to treat sore throat ${ }^{13}$. However, no oral knowledge has so far been reported on the harmful side effects relating to the use of baobab root tubers.

The presence of terpenoids and saponins in baobab root tubers agree with the previous work in Nigeria which also reported the occurrence of saponins and terpenoids in baobab root tubers ${ }^{28}$. The antimicrobial activity of baobab root has been reported to be influenced by the presence of saponins and terpenoids ${ }^{29}$. The availability of terpenoids and saponins in baobab root tubers therefore justifies their traditional application in the treatment of microbial infections. From the results of this study, baobab root tubers from all the provenances could hence be utilized to treat microbial infections. However, the varying concentration of terpenoids and saponins in baobab root tubers still needs to be considered in order to optimize their efficacy in the treatment of microbial infections. Terpenoids are precursors in the human body which help to produce steroids like sex hormones such as testosterone ${ }^{30}$. The traditional use of $A$. digitata root tubers either for food or medicinal purposes could hence be helpful in increasing testosterone levels in males with fertility problems. Because of strong concentrations of terpenoids, baobab root tubers could be utilized to optimize male testosterone levels. It has been reported that saponins regulate blood sugar levels in the human body ${ }^{23}$. Presence of saponins in baobab root tubers from all the provenances could therefore defend their traditional use in treating diabetes. Flavonoids are chemical compounds with antidiarrheal activity ${ }^{31}$. Absence of flavonoids points out that baobab root tubers from all the five provenances may not be a practical remedy for treating diarrhea. Alkaloids are chemical compounds mostly containing basic nitrogen atoms and are used as a remedy for gout with analgesic and anti-malarial activity $^{32,33}$. The absence of alkaloids in baobab root tubers from all the provenances therefore shows that they are not an ideal remedy for treating gout, malaria and for eliminating body pain. Absence of alkaloids and flavonoids differs with other findings which have proved the availability of alkaloids and flavonoids in baobab root and attributed their variations to environmental differences and maturity of the plant part used $^{28}$. In the current study, seedlings were used perhaps before the plants started reserving or storing alkaloids and flavonoids in the roots.

\section{Conclusion and Recommendations}

This study has revealed that baobab root tubers are an important source of magnesium, calcium, potassium, iron, copper, zinc and manganese which are required for the proper functioning of the human body. But baobab root tubers have also shown to contain heavy metals $(\mathrm{Pb}$ and $\mathrm{Cd}$ ), which are not required in considerable doses by the human body. Baobab root tubers have demonstrated to possess important phytochemicals such as terpenoids and saponins which are crucial in the treatment of ailments. However, alkaloids and flavonoids were absent. The mineral and phytochemical composition of baobab root tubers has proved to be distinct across geographical localities of Malawi when raised in a similar environment. Therefore, because of these differences, the use of baobab root tubers for food and medicinal purposes should not be generalized. Further studies are required to establish the causes of high lead and cadmium levels in baobab root tubers. In addition, domestication efforts must consider variation in mineral and phytochemical composition of baobab root tubers if target ideotypes of baobab are to be produced.

\section{Acknowledgement}

This writing of this manuscript was jointly supported by the Africa Center of Excellence in Public Health and Herbal Medicine (ACEPHEM), College of Medicine, University of Malawi and Consortium for Advanced Research Training in Africa, (CARTA). ACEPHEM receives finances through a grant from the Malawi Government from an IDA Credit facility (ACE II) (P151847) Credit number 5802-MW. CARTA is jointly led by the African Population and Health Research Center and the University of the Witwatersrand and funded by the Carnegie Corporation of New York (Grant No--B 8606.R02), Sida (Grant No:54100029), the DELTAS Africa Initiative (Grant No: 107768/Z/15/Z). The DELTAS Africa Initiative is an independent funding scheme of the African Academy of Sciences (AAS)'s Alliance for Accelerating Excellence in Science in Africa (AESA) and supported by the New Partnership for Africa's Development Planning and Coordinating Agency (NEPAD Agency) with funding from the Welcome Trust (UK) (Grant No: 107768/Z/15/Z) and the UK government, “ The authors are also grateful to Mzuzu University for providing space to sown baobab seeds and conduct phytochemical analyses. Statements made and views expressed are solely the responsibility of the authors.

\section{References}

1. Rahul J, Jain MK, Singh SP, Kamal RK, Anurada Naz A, Gupta AK, et al. Adansonia digitata L. (baobab): A review of traditional information and taxonomic description. Asian Pac. J. Trop. Biomed. 2015 ;5(1):79-84. doi: 10.1016/S2221-1691(15)30174-X.

2. Diop AG, Sakho M, Dornier M, Cisse M, Reynes M. The African baobab tree (Adansonia digitata L.): Principle characteristics and uses. Fruits. 2005 ;61:55-69. doi: 10.1051/fruits:2006005.

3. Kamatou GPP, Vermaak I, Viljoen AM. An updated review of Adansonia digitata: A commercially important African tree. S. Afr. J. Bot $2011 ; 77(4): 908-919$. doi: 10.1016/j.sajb.2011.08.010.

4. Munyebvu F. Abundance, structure and uses of baobab (Adansonia digitata L.) populations in Omusati region [dissertation]. University of Namibia; 2011.

5. Sharma BK, Bhat AA, Jain AK. Adansonia digitata L. (Malvaceae): A threatened tree species of medicinal importance. Medicinal plants. 2015;7(3):173-181. doi: 10.5958/0975-6892.2015.00025.8.

6. Sugandha S, Varsha P, Shashi R. Medicinal uses of Adansonia digitata L: An endangered tree species. J. Pharm. Sci. Innov. 2013;2(3):14-16. doi: $10.7897 / 2277-4572.02324$.

7. Cuni Sanchez A. The baobab tree in Malawi. Fruits. 2011;66(6):405416. doi: $10.1051 /$ fruits/2011055.

8. Nouruddeen ZB, Muhammed AS, Ghazali HM, Karim S. Baobab tree (Adansonia digitata L.) parts: Nutrition, applications in food and uses in ethno-medicine - A review. Ann. Nutr. Disord.\& Ther. 2014;1(3):1011. doi: 10.13140/RG.2.1.1966.7602.

9. Gebauer J, El-Siddig K, Ebert G. Baobab: A review on a multipurpose tree with promising future in the Sudan. Gartenbauwissenschaft. 2002;67(4):155-160. doi: 10.1007/s10341-017-0328-8.

10. De Caluwé E, Halamova K, Van Damme P. Adansonia digitata L. A review of traditional uses, phytochemistry and pharmacology. Afrika Focus. 2010;23(1):11-51. doi: https://doi.org/10.21825/af.v23i1.5037.

11. Emmanuel MM, Didier DS. Traditional knowledge on medicinal plants use by ethnic communities in Douala, Cameroon. European J. Med. Plants. 2012;2(2):159-176. doi: http://dx.doi.org/10.9734/ejmp. 
12. Munthali CRY. Use, physiology and genetic characterization of selected natural populations of Adansonia digitata in Malawi. [dissertation]. Stellenbosch University; 2011.

13. Morris B, Msonthi JD. Chewa medical botany: A study of herbalism is southern Malawi [Internet]. International African Institute; 1996 [cited 2017 Dec 12]. Available from: https://www.amazon.com/ChewaMedical-Botany-Monographs-International/dp/3825826376

14. Hardcastle PD. A preliminary silvicultural classification of Malawi [Internet]. Forestry Research Institute of Malawi; 1978 [cited 2018 Jan 2]. Available from: http://www.worldcat.org/

15. Osborne DR, Voogt P. The analysis of nutrients in foods. The academic press: London; 1978.

16. Harborne JB. Methods of plant analysis: Phytochemical methods. Chapman and Hall: London; 1973.

17. Sofowara AE. Medicinal plants and traditional medicine in Africa. Spectrum Books Ltd: Ibadan; 1993.

18. Trease GE, Evans WC. Pharmacognosy. 2nd ed. Braille Tiridel and Macmillan Publishers; 1989.

19. Ceyhan E, Kahraman A, Önder M. Environmental effects on quality parameters of plant products. Proceedings of the International Conference on Biology, Environment and Chemistry; 2011 Dec 28-30; IACSIT Press: Singapore; 2011.

20. Zobel B, Talbert J. Applied forest tree improvement. John Wiley and Sons; 1984.

21. Tizioto PC, Taylor JF, Decker JE, Gromboni CF, Mudadu MA, Schnabel RD, et al. Detection of quantitative trait loci for mineral content of Nelore longissimus dorsi muscle. Genet. Sel. Evol. 2015;47:15. doi: 10.1186/s12711-014-0083-3.

22. Florkowski WJ, Shewfelt RL, Brueckner B, Prussia SE, editors. 2nd ed. Postharvest handling: A systems approach. Academic press; 2009.

23. Salunkhe DK, Bolin HR, Reddy NR, editors. 2nd ed. Storage, processing, and nutritional quality of fruits and vegetables. CRC Press;
1991

24. Ijeomah AU, Ugwuona FU, Ibrahim Y. Nutrient composition of three commonly consumed indigenous vegetables of north-central Africa. NJAFE. 2012;8(1):17-21.

25. Phytotrade Africa. Nutritional evaluation of baobab dried fruit pulp and its potential health benefits. Leatherhead Food Research. 2009 Jul.13p.

26. Arredondo M, Nunez MT. Iron and copper metabolism. Mol Aspects Med. 2005;26 (4-5):313-327. doi: 10.1016/j.mam.2005.07.010.

27. Hutton M, Kingdom U. Human health concerns of lead, mercury, cadmium and arsenic. London: United Kingdom; 1987.

28. Fasola TR, Iyamah PC. Comparing the phytochemical composition of some plant parts commonly used in the treatment of Malaria. Int. J. Pure Appl. Sci. Technol. [Internet]. 2014 Jan [cited 2017 Dec 21];21(1):[about 1 p.]. Available from: www.ijopaasat.in

29. Masola SN, Mosha RD, Wambura PN. Assessment of antimicrobial activity of crude extracts of stem and root barks from Adansonia digitata (Bombacaceae) (African baobab). Afr. J. Biotechnol. 2009;8(19):50765083. 30. Prior RL, Cao G. Antioxidant phytochemicals in fruits and vegetables: Diet and health implications. J. Agric. Food Chem. 1999;35(4):588-592. doi: 10.3923/rjmp.2014.50.81.

31. Ivanova DG, Tasinov O, Vankova D, Kiselova-Kaneva Y. Antioxidative potential of Agrimonia eupatoria L. Science \& Technologies [Internet]. 2011 Jul [cited 2018 Jan];1(1):[about 1 p.]. Available from: https://www.researchgate.net/publication/235278128

32. Kakhia TI (Adana University). Alkaloids and alkaloids plants. Industry Joint Research Center; 2011 Mar.

33. Woolley JG. Plant alkaloids. In: Encyclopedia of Life Sciences. Nature Publishing Group, John Wiley \& Sons. 2001. pp. 1-11 